\title{
INFEKSI NEMATODA USUS PADA ANAK USIA 6-12 TAHUN DI KAMPUNG CIPAMURUYAN DESA SANGHIANGDENGDEK KECAMATAN PULOSARI PANDEGLANG
}

\author{
*Syahrial Harun ${ }^{1)}$, Sumiati Bedah ${ }^{1)}$, Iis Fatan Fasihat ${ }^{1)}$ \\ ${ }^{1}$ Program Studi Analis Kesehatan, Fakultas Kesehatan, Universitas Mohammad Husni Thamrin \\ Correspondence author: Syahrial Harun, syahrialharun7@gmail.com, Jakarta, Indonesia
}

\begin{abstract}
ABSTRAK
Prevalensi infeksi Nematoda Usus masih tinggi terutama pada anak-anak. Kecacingan yang disebabkan oleh cacing yang ditularkan melalui tanah atau Soil Transmitted Helminths, yaitu Ascaris lumbricoides (cacing gelang), Trichuris trichiura (cacing cambuk), Ancylostoma duodenale dan Necator americanus (cacing tambang). Faktor yang menyebabkan tingginya infeksi Nematoda Usus adalah personal hygine dan fasilitas sanitasinya yang masih rendah terutama yang belum memiliki jamban dan kebiasaan buang air besar di tanah. Penelitian ini bertujuan untuk mengetahui prevalensi infeksi nematoda usus dan spesies nematoda usus di Kampung Cipamuruyan. Populasi ini diambil dari seluruh anak usia 6-12 tahun di Kampung Cipamuruyan Desa Sanghiangdengdek Kecamatan Pulosari. Pemeriksaan secara mikroskopik terhadap 52 sampel feses anak-anak dan dilakukan wawancara untuk mengetahui karakteristik dan perilaku kebersihan anak. Metode dalam penelitian ini adalah metode sedimentasi (pengendapan). Berdasarkan hasil penelitian didapat besar angka infeksi Nematoda Usus yang ditularkan melalui tanah adalah 100\% (52/52). Spesies cacing yang ditemukan ada 3 yaitu Ascaris lumbricoides sebanyak 28 (53,85\%), Trichuris trichiura sebanyak 46 (88,46\%) dan Cacing tambang sebanyak $2(3,85 \%)$, diantara spesies yang didapat ada infeksi tunggal dan infeksi ganda. Data personal hygiene dan fasilitas sanitasi berdasarkan kuisioner didapatkan tingkat personal hygiene baik dengan hasil positif sebanyak 17 responden dan buruk dengan hasil positif sebayak 35 responden. Sedangkan pada fasilitas sanitasi, yang mempunyai jamban dengan jumlah positif sebanyak 4 responden dan yang tidak memiliki jamban dengan jumlah positif sebanyak 48 responden.
\end{abstract}

Kata kunci : Nematoda Usus, kebersihan anak, STH.

\section{ABSTRACT}

The prevalence of Intestinal Nematode infection is still high especially in children. Worms transmitted by soil transmitted helminths include Ascaris lumbricoides (roundworms), Trichuris trichiura (whipworms), Ancylostoma duodenale and Necator americanus (mineworms). The factors that cause high intestinal nematode infection are personal hygine and its low sanitation facilities especially those that do not have latrines and habits of defecate in the soil. This research aims to find out the prevalence of intestinal nematode infection and intestinal nematode species in Cipamuruyan Village. This population is taken from all children aged 6-12 years in Cipamuruyan Village Sanghiangdengdek Village Pulosari Sub-District. Microscopic examination of 52 samples of children's faeces and interviews were conducted to find out the characteristics and behaviors of the child's hygiene. The method in this study is the method of sedimentation (precipitation). Based on the results of the study obtained a large number of intestinal Nematode infections transmitted through the soil is $100 \%$ (52/52). Worm species found there are 3 ascaris lumbricoides as many as 28 (53.85\%), Trichuris trichiura as many as 46 (88.46\%) and Mineworms as many as 2 (3.85\%), among the species found there is a single infection and multiple infections. Personal hygiene data and sanitation facilities based on questionnaires obtained a good level of personal hygiene with positive results as many as 17 respondents and bad with positive results of 35 respondents. Meanwhile, in sanitation facilities, which have a positive number of latrines as many as 4 respondents and who do not have latrines with a positive number of 48 respondents.

Keywords : Intestinal Nematodes, child hygiene, STH.

Open Journal System (OJS): journal.thamrin.ac.id

http://journal.thamrin.ac.id/index.php/anakes/issue/view/34 


\section{PENDAHULUAN}

Di Indonesia masih banyak penyakit yang merupakan masalah kesehatan, salah satu diantaranya ialah cacing perut yang ditularkan melalui tanah, prevalesi cacingan di Indonesia pada umumnya masih sangat tinggi, terutama pada golongan penduduk yang kurang mampu mempunyai resiko tinggi terjangkit penyakit ini (Kepmenkes No: 424/Menkes/SK/VI/2006 : 1).

Penyakit cacingan tersebar luas dipedesaan maupun di perkotaan. Angka infeksi tinggi, tetapi intensitas infeksi (jumlah cacing dalam perut) berbeda. Hasil survei cacingan di Sekolah Dasar di beberapa provinsi pada tahun 1961-1991 menunjukan prevalensi sekitar 60\%-80\% sedangkan untuk semua umur berkisar antara 40\%-60\%. Hasi survei Subdit Diare pada tahun 2002 dan 2003 pada 40 SD di 10 provinsi menunjukan prevalensi berkisar antara 2,2\%-96,3\% (Kepmenkes No: 424/Menkes/SK/VI/2006 : 3 ).

Indonesia masih memiliki banyak penyakit yang merupakan masalah kesehatan, salah satu diantaranya adalah cacing yang ditularkan melalui tanah, yaitu Ascaris lumbricoides (cacing gelang), Trichuris trichiura (cacing cambuk), Ancylostoma duodenale dan Necator americanus (cacing tambang). Prevalensi cacingan di Indonesia pada umumnya masih sangat tinggi, terutama pada golongan penduduk yang kurang mampu dengan sanitasi yang buruk. Prevalensi bervariasi antara 2,5\% - 62\% (Permenkes No 15, 2017 : 17).

Manusia merupakan hospes definitif beberapa nematoda usus (cacing perut), yang dapat mengakibatkan masalah bagi kesehatan masyarakat. Diantara cacing perut terdapat sejumlah species yang ditularkan melalui tanah Soil Transmitted Helminths (STH). Pada umumnya telur cacing bertahan pada tanah yang lembab, tumbuh menjadi telur yang infektif dan siap untuk masuk kedalam tubuh manusia yang merupakan hospes definitifnya (Kepmenkes No: 424/Menkes/SK/VI/2006 : 6)

Infeksi cacing Ascaris lumbricoides adalah 16 minggu, sedangkan Trichuris trichiura adalah 41 minggu. Ini terjadi di lingkungan anak yang berdefekasi di saluran air terbuka dan dihalaman sekitar rumah. Kebiasaan defekasi sekitar rumah, makan tanpa cuci tangan, bermain-main di tanah di sekitar rumah, akan menyebabkan anak terus menerus mendapat infeksi. Dengan demikian golongan rawan infeksi spesies cacing ini adalah anak balita (Taniawati, Margono, Susato, Abidin, $2008: 22$ ).

Kampung Cipamuruyan yang ada di Desa Sanghiangdengdek Kecamatan Pulosari Kabupaten Pandeglang Provinsi Banten, merupakan wilayah pegunungan bersuhu dingin yang memiliki lingkungan pedesaan yang masih asri mengingat daerahnya yang jauh dari perkotaan, minimnya penggunaan jamban karena tidak semua rumah memiliki jamban dan kebiasaan anak-anak yang BAB sembarangan di tanah sehingga memungkinkan ditemukan adanya parasit yang ditularkan melalui tanah atau sering disebut Soil Transmitted Helminths (STH).

Terpilihnya Kampung Cipamuruyan di Kecamatan Pulosari Kabupaten Pandeglang Banten disebabkan karena selama ini belum pernah dilakukan pemeriksaan Nematoda Usus yang ditularkan melalui tanah 
atau sering disebut Soil Transmitted Helminths (STH) pada anak usia 6-12 tahun di Kampung Cipamuruyan tersebut sehingga penulis merasa tertarik untuk melakukan pemeriksaan tersebut terhadap anak-anak untuk menemukan telur cacing ditularkan melalui tanah atau sering disebut Soil Transmitted Helminths (STH) dengan menggunakan metode Sedimentasi (Pengendapan).

\section{METODOLOGI PENELITIAN}

Pengambilan sampel dalam penelitian ini dilakukan di Kampung Cipamuruyan. Pemeriksaaan dilakukan di Laboratorium Universitas MH. Thamrin Jakarta. Penelitian dilakukan dilaboratotium parasitologi Universitas MH.Thamrin Jakarta pada Juli-Agustus 2018. Populasi adalah seluruh anak 612 tahun di Kampung Cipamuruyan Desa Sanghiangdengdek sejumlah 52 orang. Sampel adalah feses anak usia 6-12 tahun di Kampung Cipamuruyan Desa Sanghiangdengdek dengan total sampling sejumlah 52 orang. Untuk mengetahui prevalensi infeksi telur cacing nematoda usus yang ditularkan melalui tanah pada anak usia 6 - 12 tahun di Kampung Cipamuruyan Desa Sanghiangdengdek Kecamatan Pulosari Pandeglang. Maka data yang diperoleh dianalisa dengan uji presentase, dengan membagi jumlah feses yang positif mengandung telur cacing STH dibagi dengan jumlah sampel feses yang diperiksa. Hasil survei dapat digunakan untuk mengklasifikasikan tingkat endemisitas suatu daerah (Permenkes No.15, 2007 : 44).

$$
\begin{gathered}
\text { Prevalensi cacingan: } \\
=\frac{\text { Jumlah sampel tinja positif telur cacig }}{\text { Jumlah sampel tinja yang diperiksa }} \times 100 \%
\end{gathered}
$$

Untuk mengetahui tingkat personal hygiene dengan penilaian rumus dibawah ini:

interval:

$\frac{\text { (jumlah pertanyaan x nilai tertinggi) }- \text { (jumlah pertanyaan x nilai terendah) }}{2}$

interval:

$\frac{(8 \times 1)-(8 \times 0)}{2}=4$

Baik: 5-8 Buruk: 1-4

Open Journal System (OJS): journal.thamrin.ac.id 


\section{HASIL DAN PEMBAHASAN}

\section{Hasil}

\section{Gambaran Lokasi Penelitian}

Lokasi Kampung Cipamuruyan yang berada di Desa Sanghiangdengdek Kecamatan Pulosari Pandeglang merupakan wilayah pegunungan bersuhu dingin yang memiliki lingkungan pedesaan, mengingat daerahnya yang jauh dari perkotaan dan anak-anak yang memiliki kebiasaan bermain yang higienitasnya kurang dan minimnya penggunaan WC karena tidak semua rumah memiliki WC, sehingga anak-anak di kampung tersebut memiliki kebiasaan defekasi/BAB di tanah. Perilaku kebersihan pada anak dapat dinilai berdasarkan observasi, kuisioner, dan wawancara.

\section{Angka Infeksi Nematoda Usus pada Anak Usia 6-12 Tahun di Kampung Cipamuruyan Desa Sanghiangdengdek Kecamatan Pulosari Pandeglang}

Dalam penelitian ini diperiksa 52 sampel responden (anak) yang berada di kampung Cipamuruyan dan Hasil pemeriksaan feses untuk menentukan infeksi kecacingan yang disebabkan oleh Nematoda Usus yang ditularkan melalui tanah didapatkan semua responden terinfeksi 100\%(52/52).

\section{Distribusi Frekuensi Nematoda Usus Berdasarkan Spesies Cacing pada Anak Usia 6-12 Tahun di Kampung Cipamuruyan Desa Sanghiangdengdek Kecamatan Pulosari Pandeglang}

Infeksi cacing yang disebabkan oleh nematoda usus yang ditularkan melalui tanah berdasarkan spesies pada anak usia 6-12 tahun di kampung Cipamuruyan Pandeglang. Yang terinfeksi Ascaris lumbricoides sebanyak 28 (53,85\%) diantaranya Infeksi tunggal 4 (7,69\%) dan infeksi ganda Ascaris lumbricoides \& Trichuris trichiura 24 (46,15\%), Trichuris trichiura sebanyak 48 (92,31\%) diantaranya Infeksi tunggal 22 (42,31\%) dan infeksi ganda Ascaris lumbricoides \& Trichuris trichiura 24 (46,15\%), Infeksi tunggal pada Cacing tambang (Ct) sebanyak $0(0 \%)$ sedangkan pada infeksi ganda Trichuris trichiura \& Cacing tambang sebanyak 2 (3,85\%). Untuk lebih jelasnya dapat dilihat pada Tabel di bawah ini: 
Tabel 2.

. Distribusi Frekuensi Nematoda Usus Berdasarkan Spesies Cacing pada Anak Usia 6-12 Tahun di Kampung Cipamuruyan Desa Sanghiangdengdek Kecamatan Pulosari Pandeglang

\begin{tabular}{lcc}
\hline \multicolumn{1}{c}{ Spesies Telur Cacing } & \multicolumn{2}{c}{ Hasil pemeriksaan } \\
\cline { 2 - 3 } & Jumlah Positif & Persentase \\
\hline Infeksi Tunggal: & 4 & $7,69 \%$ \\
Ascaris lumbricoides & 22 & $42,31 \%$ \\
Trichuris trichiura & 0 & $0 \%$ \\
Cacing Tambang & & \\
\hline Infeksi Ganda: & 24 & $46,15 \%$ \\
Ascaris lumbricoides dan Trichuris trichiura & 2 & $3,85 \%$ \\
Trichuris trichiura dan Cacing Tambang & 52 & $100 \%$ \\
\hline Jumlah & \multicolumn{2}{c}{} \\
\hline
\end{tabular}

Persentase Infeksi Nematoda Usus Berdasarkan Karakteristik Umur pada Anak Usia 6-12 Tahun di Kampung Cipamuruyan Desa Sanghiangdengdek Kecamatan Pulosari Pandeglang

Berdasarkan karakteristik usia dan jenis kelamin anak, didapatkan angka infeksi nematoda usus pada semua jenis kelamim anak laki-laki terinfeksi dan semua jenis kelamin anak perempuan terinfeksi. Semua usia 6-9 tahun terinfeksi dan semua usia 10-12 tahun terinfeksi. Untuk lebih jelasnya dapat dilihat pada Tabel di bawah ini:

Tabel 3

Persentase Infeksi Nematoda Usus Berdasarkan Karakteristik Umur pada Anak Usia 6-12 Tahun di Kampung Cipamuruyan Desa Sanghiangdengdek Kecamatan Pulosari Pandeglang

\begin{tabular}{ccccc}
\hline \multirow{2}{*}{ Karakteristik Anak } & \multicolumn{2}{c}{ Hasil Pemeriksaan (\%) } & \multirow{2}{*}{$\begin{array}{c}\text { Jumlah } \\
\text { Seluruhnya }\end{array}$} \\
\cline { 2 - 4 } & Positif & Negatif & \\
\hline \multirow{2}{*}{ Usia } & $6-9$ tahun & $25(100 \%)$ & 0 & 25 \\
\cline { 2 - 4 } & $10-12$ Tahun & $27(100 \%)$ & 0 & 27 \\
\hline
\end{tabular}

Tingkat Personal Hygiene dan Fasilitas Sanitasi Berdasarkan Kuisioner pada Anak Usia 6-12 Tahun di Kampung Cipamuruyan Desa Sanghiangdengdek Kecamatan Pulosari Pandeglang

Dari hasil kuisoner didapatkan tingkat personal hygiene baik dengan hasil positif sebanyak 17 responden dan personal hygiene buruk dengan hasil positif sebayak 35 responden. Sedangkan pada fasilitas sanitasi, yang mempunyai jamban dengan jumlah positif sebanyak 4 responden dan yang tidak memiliki jamban dengan jumlah positif sebanyak 48 responden. Untuk lebih jelasnya dapat dilihat pada Tabel di bawah ini:

Open Journal System (OJS): journal.thamrin.ac.id 
Tabel 4

Tingkat Personal Hygiene Berdasarkan Kuisioner pada

Anak Usia 6-12 Tahun di Kampung Cipamuruyan

Desa Sanghiangdengdek Kecamatan Pulosari Pandeglang

\begin{tabular}{ccc}
\hline \multirow{2}{*}{ Personal Hygiene } & \multicolumn{2}{c}{ Hasil pemeriksaan } \\
\cline { 2 - 3 } Baik & 17 & Negatif $(-)$ \\
Buruk & 35 & 0 \\
Jumlah & 52 & 0 \\
\hline Fasilitas Sanitasi & & \\
\hline Ya & 4 & 0 \\
Tidak & 48 & 0 \\
Jumlah & 52 & 0 \\
\hline
\end{tabular}

\section{Pembahasan}

\section{Berdasarkan Prevalensi}

Hasil penelitian dari 52 sampel feses anak-anak usia 6-12 tahun di kampung Cipamuruyan Desa Sanghiangdengdek Kecamatan Pulosari Pandeglang didapatkan hasil positif 52 anak (100\%), hasil ini mengidikasi bahwa adanya infeksi Nematoda Usus yang ditularkan melalui tanah pada anak usia 6-12 tahun di kampung Cipamuruyan. Angka tersebut lebih tinggi dibandingkan dengan hasil penelitian sebelumnya yang dilakukan oleh Maulidah,dkk (2016) pada siswa kelas 3-5 SDN Multatuli Rangkasbitung Kabupaten Lebak Banten dimana sampel yang diperiksa sebanyak 43 siswa dan hasil persentase terinfeksi nematoda usus sebanyak 64,44\%. Angka ini lebih tingi dari penelitian yang dilakukan oleh Dian Nur Fatonah, (2017) pada anak usia 6-12 tahun di kampung Dukuh Desa Bojong Kecamatan Bojong Kabupaten Pandeglang Banten dimana sampel sebanyak 158 dan hasil persentase terinfeksi nematoda usus sebanyak 14 siswa $(8,9 \%)$. Hal ini mungkin disebabkan oleh kebersihan pribadi anak dan keadaan lingkungan yang berbeda dan perbedaan anak-anak menjaga kebersihan pribadi. Dimana lingkungan di kampung Cipamuruyan tersebut lebih rentan terkena infeksi Nematoda Usus yang ditularkan melalui tanah mengingat kebersihan diri dan kepemilikan jamban yang masih kurang.

Walaupun daerah tersebut menurut petugas puskesmas (wawancara pribadi) pada bulan april lalu telah dilakukan pengobatan dengan diberikan obat albendazol di SDN Sanghiangdengdek. Menurut permenkes program kecacingan harus dilakukan satu kali dalam 1 tahun pada daerah yang infeksinya 
diatas $20 \%-50 \%$ sedangkan untuk daerah yang infeksinya $>50 \%$ pengobatan 2 kali dalam 1 tahun (Permenkes No. 15, $2017:$ 50).

\section{Berdasarkan Spesies}

Berdasarkan spesies (Tabel 3) yang menginfeksi anak-anak usia 6-12 tahun di kampung Cipamuruyan Desa Sanghiangdengdek Kecamatan Pulosari Pandeglang adalah infeksi tunggal Ascaris lumbricoides sebanyak 4 (7,69\%) dan infeksi tunggal Trichuris trichiura sebanyak 22 (42.31,54\%), Cacing tambang sebanyak 0 (0\%), infeksi ganda Ascaris lumbricoides dan Trichuris trichiura 24 (46,15\%), dan Trichuris trichiura dan cacing tambang 2 (3,85\%). Spesis yang didapatkan lebih tinggi dibanding penelitian Maulidah,dkk (2016) pada siswa kelas 3-5 SDN Multatuli Rangkasbitung, Kabupaten Lebak dimana sampel sebanyak 45 sampel dengan hasil positif 29 siswa dengan spesies yang didapat adalah Ascaris lumbricoides (33,33\%), cacing tambang (11,11\%) dan Trichuris trichiura $(15,56 \%)$. Sedangkan untuk infeksi campuran ditularkan oleh Ascaris lumbricoides dan Trichuris trichiura yaitu 2 siswa $(4,44 \%)$.

Kemungkinan tingginya infeksi nematoda usus karena kebiasaan anak-anak yang kurang memperhatikan kebersihannya seperti tidak mencuci tangan sebelum makan, jarang memotong kuku dan kebiasaan BAB di tanah sehingga spesies Ascaris lumbricoides, Trichuris trichiura dan Cacing tambang dapat menginfeksi mereka.

Infeksi terjadi karena menelan telur yang telah berembrio melalui tangan, makanan, atau minuman yang telah terkontaminasi, langsung dengan debu, hewan rumah atau barang mainan (Irianto, 2013 : 231). Beberapa survei yang dilakukan di Indonesia menunjukkan bahwa sering kali prevalensi Ascaris yang tinggi disertai dengan prevalensi Trichuris yang tinggi pula. Ini terjadi di lingkungan anak yang berdefekasi di saluran terbuka dan di halaman sekitar rumah. Untuk penderita campuran yang disebabkan oleh Ascaris lumbricoides dan Trichuris trichiura tidak ada dampak khusus, hanya saja pada umumnya infeksi kecacingan dapat menyebabkan gangguan gizi, anemia, gangguan pertumbuhan dan kecerdasan (Taniawati, Margono, Susanto, Abidin, $2008: 22$ ).

\section{Berdasarkan Usia}

persentase karakteristik usia (Tabel 3) pada anak-anak usia 6-12 Tahun di Kampung Cipamuruyan Desa Sanghiangdengdek Kecamatan Pulosari Pandeglang didapatkan hasil positif infeksi nematoda usus pada jenis kelanim anak laki-laki sebanyak 100\% (32/32) dan jenis kelamin anak perempuan sebanyak 100\% (20/20). Sedangkan pada usia 6-9 tahun sebanyak 100\% (25/25) dan usia 10-12 tahun sebanyak 100\% (27/27). Angka tersebut lebih tinggi dibandingkan dengan penelitian sebelumnya yang dilakukan oleh Dian Nur Fatonah, (2017) pada anak usia 6-12 tahun di kampung Dukuh Desa Bojong Kecamatan Bojong Kabupaten Pandeglang Banten dimana sampel sebanyak 158 dan didapatkan hasil

Open Journal System (OJS): journal.thamrin.ac.id 
positif infeksi Nematoda Usus pada jenis kelamin laki-laki sebanyak 10,3\% (8/78) dan perempuan 7,5\% (6/80), sedangkan pada umur 6-9 tahun sebanyak 10,3\% (11/107) dan 10-12 sebanyak 5,9\% $(3 / 51)$.

Anak 10-12 tahun mempunyai tingkat berfikir akan kesehatan dan kebersihan akan diri sendiri dibandingkan anak umur 6-9 tahun yang masih belum berfikir akan kebersihan diri dan masih ada dimasa aktif pertumbuhan dari balita menuju anak-anak. Tetapi karena lingkungannya yang masih buruk sehingga kemungkinan terjadinya infeksi yang tinggi.

\section{Berdasarkan Tingkat Personal Hygiene dan Fasilitas Sanitasi}

Tingkat personal hygiene dan fasilitas sanitasi (tabel 4), tingkat personal hygiene baik dengan hasil positif sebanyak 17 dan buruk dengan hasil positif sebayak 35. Sedangkan pada fasilitas sanitasi, yang mempunyai jamban dengan jumlah positif sebanyak 4 responden dan yang tidak memiliki jamban dengan jumlah positif sebanyak 48 responden. Karena kepemilikan jamban yang masih sedikit inilah yang memungkinkan memicu adanya infeksi nematoda usus yang ditularkan melalui tanah.

Kurangnya jamban keluarga menimbulkan pencemaran tanah dengan tinja di sekitar halaman rumah, di bawah pohon, di tempat mencuci dan di tempat pembuangan sampah. Hal ini akan memudahkan terjadinya infeksi (Supali, Margono, Alisah, Abidin, 2008 : 9).

Bila keadaan ekonomi baik, maka ia akan membuat rumah yang lebih baik, jamban yang sehat, mengirim anak-anaknya ke sekolah upaya lebih mengetahui masalah kesehatan, sehingga dapat merubah perilaku ke arah perilaku hidup bersih dan sehat (Permenkes No.15, 2017 : 20).

Kita harus menjaga kebersihan diri dan lingkungan, sebagai makhluk hidup harus tetap waspada terhadap infeksi disekitar kita, apalagi jika kita BAB sembarangan. Karena jika tidak memperhatikan kebersihan tangan sebelum makan baik menggunakan sabun atau tanpa sabun serta keberisihan kuku maka telur cacing akan masuk ke dalam tubuh dan berkembang biak di dalam tubuh.

\section{SIMPULAN}

Dari hasil pemeriksaan yang dilakukan terhadap sampel anak-anak usia 6-12 tahun di Kampung Cipamuruyan Desa Sanghiangdengdek Kecamatan Pulosari Pandeglag dapat disimpulkan sebagai berikut: Prevalensi infeksi Nematoda Usus pada 52 responden 100\% (52/52). Spesies cacing nematoda usus yang ditemukan adalah Infeksi tunggal Ascaris lumbricoides sebanyak 4 (7,69\%) dan infeksi ganda Ascaris lumbricoides \& Trichuris trichiura sebanyak 24 (46,15\%), Infeksi tunggal Trichuris trichiura sebanyak 22 (42,31\%) dan infeksi ganda Ascaris lumbricoides \& Trichuris trichiura sebanyak 24 (46,15\%), Infeksi tunggal pada Cacing tambang sebanyak sebanyak $0(0 \%)$ dan infeksi ganda Trichuris trichiura \& Cacing tambang sebanyak 2 (3,85\%). Pada anak 6-12 tahun di Kampung 
Cipamuruyan mempunyai tingkat prilaku dan personal hygiene yang buruk yaitu sebanyak 35 responden dari 52 responden, dan fasilitas sanitasi yang masih kurang yaitu hanya 4 responden yang memiliki jamban dari 52 responden.

\section{UCAPAN TERIMA KASIH}

Penulis mengucapkan terima kasih kepada petani kelapa sawit di Desa Pauh Menang Kecamatan Pamenang Kabupaten Merangin, Jambi, Kepala Laboratorium Biologi Fakultas Kesehatan Universitas MH Thamrin Jakarta dan Prodi D III Analis Kesehatan Fakultas Kesehatan Universitas MH Thamrin. dalam penelitian ini.

\section{DAFTAR PUSTAKA}

1. Azizah, Ifa Nur., Setyowati, W ., 2011, Hubungan Tingkat Pengetahuan Ibu Pemulung Tentang Personal Hygiene dengan Kejadian Skabies pada Balita di Tempat Pembuangan Akhir Kota Semarang, Dinamika Kebidanan, Semarang

2. Depkes RI,. 2006. Surat Keputusan Menteri Kesehatan Nomor 424/MENKES/SK/VI/2006 tentang Pedoman Pengendalian Cacingan.

3. Fatonah, D, N., 2017. Infeksi Nematoda Usus Yang Ditularkan Melalui Tanah Dan Hubungannya Dengan Perilaku Kebersihan Pada Anak Usia 6-12 Tahun Di Kampung Dukuh Desa Bojong Kecamatan Bojong Kabupaten Pandeglang Banten

4. Fuad, F,. 2013. Perbandingan Pemeriksaan Telur Soil Transmitted Helminth pada Tanah dengan Metode Flotasi NaCl Jenuh (Willis). Semarang: UNIMUS

5. Hadjaja, Pinardi., Natadisastra, Djaenudin (Editor)., 2005, Parasitologi Kedokteran, Penerbit Buku Kedokteran ECG, Jakarta

6. $\quad$ https://pandeglangkab.bps.go.id

7. Irianto, K., 2013, Parasitologi Medis,Penerbit Alfa Beta, Bandung.

8. Jonas, Y., 2012. Hubungan Sosial Ekonomi Keluarga Dengan Status Gizi Pada Murid Sekolah Dasar di Kabupaten Bolaang Mangondow Selatan, Skripsi PSIK FK Unsrat, Manado.

9. Kusumamihardja, S., 1992, Parasit dan Parasitosis pada Hewan Ternak dan Hewan Piaraan, Pusat Antar Universitas IPB, Bogor

10. Margono, Sri S., 2008. Parasitologi Kedokteran Edisi Keempat, Balai Penerbit FKUI, Jakarta.

11. Maulidah, M, dkk, 2016. Angka Kecacingan Pada Siswa Kelas 3-5 SDN Multatuli Rangkasbitung, Kabupaten Lebak Banten

12. Noviastuti, Aulia R.,2015. Infeksi Soil Transmitted Helminths, Fakultas Kedokteran, Universitas Lampung

13. Opusunggu, M.S., Ester, M (Editor)., 2007. Pedoman Pemeriksaan Parasit, Balai Penerbit Buku Kedokteran ECG

14. Oswari. E., 1991. Penyakit dan Penanggulangannya, Gramedia, Jakarta.

15. Peraturan Menteri Kesehatan RI., 2017. Nomor 15 tentang penanggulangan kecacingan

16. Safar, R., 2009 Parasitologi Kedokteran:Prozologi, Entomologi, dan Helmintologi, Yrama Widya, Jakarta.

17. Setya, Adi K., Mardella, Eka A (Editor)., 2014. Parasitologi Praktik Analis Kesehatan, Balai Penerbit Buku Kedokteran ECG, Jakarta.

18. www.dpd.cdc.gov/ 